\title{
Bariatrik cerrahi sonrası gıda intoleransı
}

\author{
Neslihan AĞBABA ${ }^{\mathrm{a}}$, Burcu ATEŞ ÖZCAN ${ }^{\mathrm{b}}$
}

\section{ÖZET}

Obezite, vücutta aşırı yağ birikimi olarak tanımlanan dünya çapında bir sağlık sorunudur ve tedavi edilebilen bir hastalıktır. Obezitenin birçok tedavi türü vardır. Yeterli ağırlık kaybının sağlanamadığı durumlarda; günümüzde popülaritesi giderek artan bariatrik cerrahi altın standart olarak kabul edilen yöntemdir. Bariatrik cerrahi sonrası beslenme takibi çok önemlidir ve multidisipliner bir yaklaşım gerektirir. Postoperatif dönemde beslenme ile ilgili bazı sorunlar yaşanabilir. Bunlardan biri gıda intoleransıdır. Araştırmalar; başta kırmızı et olmak üzere beyaz et, salata, sebze, ekmek, pirinç, makarna ve balık gibi gıdaların tüketiminde hastaların intolerans yaşadığını göstermektedir. Gıda intoleransı sonucu vitamin eksiklikleri, yetersiz protein alımı ve malnutrisyon ile diyet kalitesi ve hastaların hayat kalitesi kötüleşebilir. Bariatrik cerrahi sonrası yaşanabilecek sorunların tedavisi ve sağlığın korunmasının sürekliliği için hastalar postoperatif uzun takip edilmelidir.

Anahtar kelimeler: Bariatrik cerrahi, gida intolerans1, postoperatif beslenme

\section{Food intolerance after bariatric surgery}

\begin{abstract}
Obesity is a worldwide health problem that is defined as excess fat accumulation in the body and is a treatable disease. There are many types of treatment for obesity. Bariatric surgery treatments are accepted as the gold standard in cases in which sufficient weight loss cannot be achieved. The popularity of surgical treatments are increasing day by day. Nutrition followup after bariatric surgery is very important and it requires a multi-disciplinary approach. Some problems with nutrition may occur in the post-operative period. One of them is food intolerance. Some research shows that patients experience intolerance in the consumption of foods such as red meat, white meat, salad, vegetable, bread, rice, pasta and fish. As a result of food intolerance, vitamin deficiencies, inadequate protein intake and malnutrition may deteriorate diet quality and patients' quality of life. Patients should be followed up postoperatively for the treatment of problems that may occur after bariatric surgery and for the continuity of health protection.
\end{abstract}

Keywords: Bariatric surgery, food intolerance, postoperative nutrition

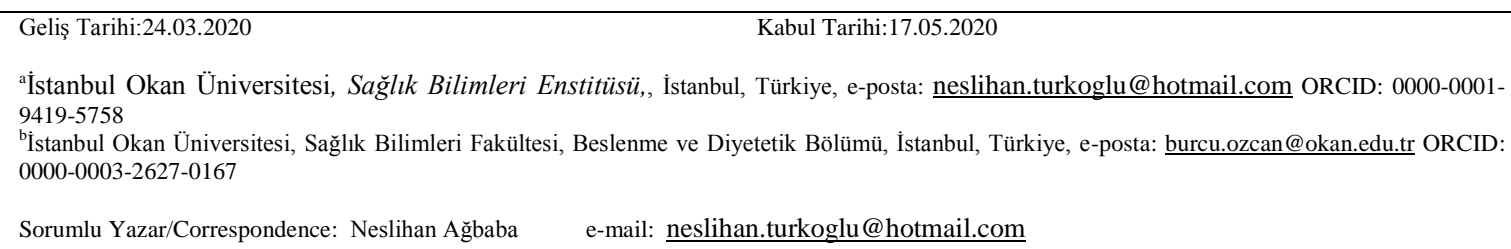

Atıf: Ağbaba N, Ateş Özcan B. Bariatrik cerrahi sonrası gıda intoleransı. Sağlık ve Yaşam Bilimleri Dergisi 2020;2(1):16-21.

Citation: Agbaba N, Ates Ozcan B. Food intolerance after bariatric surgery. Journal of Health and Life Sciences 2020;2(1):16-21. 


\section{GíRiş}

Son yıllarda görülme sıklığı giderek artan obezite çok faktörlü bir halk sağlığ 1 sorunudur. ${ }^{1}$ Dünya Sağlık Örgütü (DSÖ)'ne göre obezite, sağlık için risk oluşturan vücutta aşırı veya anormal yağ birikimi olarak tanımlanır. Obeziteyi belirlemek için DSÖ’nün formüle ettiği indeks kullanılmaktadır. Beden Kütle İndeksi (BKI) olarak bilinen bu indeks, kişinin kilogram cinsinden ağırlığının, metre cinsinden boyunun karesine $\left(\mathrm{BKI}=\mathrm{kg} / \mathrm{m}^{2}\right)$ bölünmesi ile hesaplanmaktadir. $\mathrm{Bu}$ indekse göre bireylerin BKI değerinin 20-25 aralığında olması normal kilolu, 30 ve üzerindeki değerlerde olması ise obez olarak tanımlanmaktadır. ${ }^{2}$ Obezitenin tedavisindeki amaç, yeterli bir vücut ağırlığı kaybı hedeflenerek, bireylerin obezite ile ilişkili morbidite ve moralite riskini azaltarak yeterli ve dengeli beslenme alışkanlığ kazandırmak ve yaşam kalitelerini yükseltmektir. ${ }^{3}$ T1bbi beslenme tedavisi, egzersiz tedavisi, farmakolojik tedavi, bilişsel davranışçı terapi ve cerrahi tedavi; obezite tedavisi yöntemleridir. ${ }^{4-6}$

\section{Bariatrik Cerrahi}

Bariatrik cerrahi prosedürleri, midenin alabileceği gida miktarını kısıtlayarak, besin maddelerinin malabsorbsiyonuna neden olarak veya hem gastrik kisitlama hem de malabsorpsiyonun kombinasyonuyla kilo kaybına neden olur. Bariatrik prosedürler sıklıkla hormonal değişikliklere neden olur. Günümüzde bariatrik ameliyatların çoğu minimal invaziv teknik (laparoskopik cerrahi) ile yapılmaktadır. En yaygın bariatrik cerrahi prosedürleri gastrik bypass, laparoskopik sleeve gastrektomi (LSG), ayarlanabilir gastrik bant (AGB) ve duodenal switch ile biliopankreatik diversiyondur (BPD/DS). Her ameliyatın kendine özgü avantajları ve dezavantajları vardır. ${ }^{7}$ Bariatrik cerrahi için gerekli şartlar Amerika Birleşik Devletleri (ABD) Ulusal Sağlık Enstitütüsü'nün (NIH) 1991 yılındaki konsensus kararlarında belirlenmiştir. Bu şartlar;

- $\quad$ BKI $>40 \mathrm{~kg} / \mathrm{m}^{2}$ veya $\mathrm{BKI}>35 \mathrm{~kg} / \mathrm{m}^{2}$ birlikte metabolik sendrom varlığ 1

- Ameliyatın risklerinin kabul edilebilir olmas1

- Cerrahi dışındaki obezite tedavilerinin başarısız olması

- Psikiyatrik olarak stabil olunması, alkol ve ilaç bağımlılı̆̆ olmaması

- Hastanın iyi motivasyonlu olması, ameliyatı ve sekellerini biliyor olması

- Cerrahinin getireceği yaşamı engelleyecek medikal problemlerin olmamas1

- Kontrolsüz psikiyatrik ve depresif bozukluğun olmamas1

- Aile ve sosyal çevre desteğinin tam olmasıdır. ${ }^{8}$

\section{Bariatrik Cerrahi Sonrası Beslenme}

Bariatrik cerrahi sonrası beslenme programının amacı iki yönlüdür. İlk olarak, ameliyat sonrası doku iyileşmesini ve vücut ağırlık kaybı sırasında yağsız vücut kütlesinin korunmasını desteklemek için yeterli enerji ve besin ögelerinin alınmasıdır. İkincisi, ağırlık kaybı sağlanırken tüketilen yiyecek ve içeceklerin, reflü, beklenenden daha erken doyma hissi ve dumping sendromu gibi sorunların görülme risklerini en aza indirmektir. Birçok cerrahi yöntem sonrası bu hedefleri gerçekleştirmek için farklı diyetler uygulanmaktadır. Uygulanan diyetler, normal beslenmeye geçiş sürecini evrelendirerek bireyin besinleri daha iyi tolere edebilmesini sağlamaktadır. Bireylerin metabolizmasına ve geçirdikleri cerrahi türüne bağlı olarak beslenme evrelerinin uygulama süresi değişmektedir., ${ }^{9,10} \mathrm{Bu}$ kademeli diyetlerde önemli olan nokta hastanın sıvı, protein ve diğer makro-mikro besin öğeleri ihtiyacını kısa sürede tamamlayabilmek, yağsı kas kütlesinde kaybı engellemek ve protein malnutrisyonunun önlenmesini sağlamaktır. Obezitenin karmaşıklığı, çok sayıda kriterin mevcudiyeti ve ameliyat sonrası yaşam tarzı değişikliğinin önemi sebebiyle multidisipliner bir ekip tarafından hastaların değerlendirilmesi, takip edilmesi ve eğitim verilmesi gerekmektedir. ${ }^{11,12}$

\section{Bariatrik Cerrahi Sonrası Gıda İntoleransının Nedenleri}

Tüm batı ülkelerinde morbid obezite prevalansının artmasıyla birlikte her yıl gerçekleştirilen bariatrik operasyon sayısı hızla artmaktadır. Geleneksel olarak, farklı prosedürlerin sonuçları çoğunlukla ağırlık kaybı temelinde değerlendirilmiştir. ${ }^{13}$ Ortaya çıkan ağırlık kaybına ek olarak, bu operasyonlar hipertansiyon, lipit anormallikleri, açlık plazma glikozu ve tip 2 diyabet gibi metabolik sendrom ile ilişkili komorbiditeleri iyileştirebilir veya azaltabilir. ${ }^{14,15}$

Ancak bariatrik cerrahiden sonra hastalarda bazı gida maddelerinin vücutta sindirilememesi veya emilememesi nedeniyle gida intoleransı oluşur. ${ }^{16,17}$ Gıda intoleransının birçok sebebi olabilir. Bu sebepler şu şekilde sıralanabilir;

- Postoperatif hizlı yeme, yetersiz çiğneme veya yemek sırasında sıvı gıda alımı gibi yapılması istenmeyen yeme davranışındaki değişikliklerle hastanın başa çıkamaması,

- Gastrointestinal sistemdeki anatomik değişiklikler (anormal özofagus motilitesi, hızlandırılmış mide boşalması, azalmış gastrik asit sekresyonu ve damping sendromu)

- Bariatrik tekniğin türü (AGB'de bandın sıkılığg, bant erozyonu, kayma, Roux-enY Gastrik Bypass (RYGB) sonras1 skarlaşma ve postoperatif ödem) 
- İlk y1l kademeli olarak değişen diyet

- Bariatrik cerrahi isteyen obez hastaların, obez olmayan hastalara göre daha kötü toleransa sahip olması

- Ameliyat sonrası oluşan koku ve tat hassasiyetleri bu nedenlerden bazılaridır. $^{18-23}$

Ameliyat sonrası hastalarda g1da intoleransı ve g1da seçimlerindeki değişiklikler özellikle postoperatif ilk aylarda yetersiz protein alımına neden olabilir. ${ }^{24} \mathrm{Bu}$ eksiklik midenin büyük kısmının uzaklaştırılması sonucu azalmış mide asiditesi ve intrisik faktör düzeyine bağlı olabilir. ${ }^{11} \mathrm{Bu}$ nedenlerle bariatrik cerrahi sonrası malabsorbsiyon oluşabilir. Malabsorbsiyonlar ve eşlik eden kusma, düşük miktarda besin alımı, intolerans nedeniyle bazı spesifik yiyeceklerden kaçınma eğilimi nedeniyle; demir, $\mathrm{B}_{12}$ vitamini, folat, kalsiyum ve $\mathrm{D}$ vitamini gibi besin öğelerinin eksikliği görülebilir. ${ }^{24}$

\section{Gıda İntoleransının Sık Görüldüğü Besinler}

Kırmızı et: Bariatrik cerrahi sonrası en az tolere edilen gidalardandır. Kismen sindirimden sorumlu ana enzim olan pepsin üretiminde oluşan değişiklik ile açıklanabilir. ${ }^{16}$ Malabsorbtif prosedürlerde bağırsağın bir kısmının sindirimden dışlanması ile oluşan bağırsak bakterilerinin dengesizliği (disbiyozis) ve böylece sindirim sürecinin bozulması da sebepler arasında olabilir. Gastrik motilite ve mide asidi sekresyonunda yer alan gastrin ve ghrelin gibi hormonların salgılanmasının, protein sindirimine de zarar verebilecek cerrahi prosedürle değiştirilebileceği de dikkat çekicidir. Kırmızı et, kuru tavuk parçaları, domuz eti ve ekmek gibi çok kuru olduğu düşünülen gıdalar kusmayı tetikleyebilir. Büyük hacimli yiyecek parçalarının hızlı yutulması veya iyi çiğnenmemesi, dolgunluk veya sıkışmış yiyecek hissine sebep olması da kırmızı ete toleranslı hastalarda bu semptomun ortaya çıkmasını açıklayabilir. Bu besin grubundaki intolerans, protein malnutrisyonuna sebep olabilir. ${ }^{17-25}$ Protein malnutrisyonu daha çok RYGB, BPD/DS gibi bağırsak segmentinin uzunluğunu değiştiren malabsorbtif prosedürler sonrası görülür. ${ }^{11}$

Lif: Lif, hızlı bağırsak geçişi ile ilişkilidir. Azalmış lif alımı, bu cerrahi sonrası bağırsak geçiş süresinin daha yavaş olmasının bir nedeni olabilir. ${ }^{26}$ Uzamış bağırsak geçiş süreci de kabızlığa neden olmaktadır. ${ }^{27}$ Bazı bariatrik cerrahi türlerinin kabızlığı kötüleştirmektedir ancak bu konu ile ilgili çalışmalar sınırlıdır. ${ }^{26}$ Ayrıca intolerans, tüketiminde iyi çiğneme gerektiren nişastalı ve lifli sebzelere karşı da oluşabilir. ${ }^{28}$

Pirinç: İntoleransı postoperatif erken dönemde tanımlanmıştır. Amilaz etkisini bozan pişirme sırasında pirincin hidrasyonu ve jelatinleşmesi ile ilişkilidir. $^{17}$
Süt ve süt ürünleri: Bariatrik cerrahi sonrası laktaz enziminin salınımının azalmasına bağlı olarak veya gastik hızlı geçişten dolayı laktoz intoleransı yaygın olarak görülür. İntolerans akut veya kronik olarak oluşabilir. $^{9-29}$

\section{Bariatrik Cerrahi Sonrası Gıda İntoleransı ile İlgili Yapılan Çalışmalar}

Suter ve arkadaşları 2007 yılında; bariatrik cerrahi sonrası gıda intoleransını ölçmek için yaklaşık 300 gastrik bant ve 600 RYGB ameliyatı uygulanan hasta ile gerçekleştirilen bir anket geliştirmiştir. $\mathrm{Bu}$ anket; beslenme ile ilgili öznel memnuniyet, farklı gidalara tolerans veya kusma sıklığı gibi farklı konuları da analiz ederek küresel bir puan vermektedir. Dört bölümden oluşan tek sayfalık bir ankettir. Ankette puanlama yapılabilecek üç kısım vardır. İlk kısım cevapları çok zayıf, zayıf, kabul edilebilir, iyi ve mükemmel olan ve sirasıyla 1 ile 5 arasında puan verilen beslenme ile öznel memnuniyet kısımdır. İkinci kısım kırmızı et, beyaz et, salata, sebze, ekmek, pirinç, makarna ve balık için toleransın sorgulandı $\breve{g} 1$; kolayca yeme, bazı zorluklarla yeme ve asla yiyememe seçeneklerine sırasıyla 2 ile 0 arasında puan verildiği kısımdır. Üçüncü kısımda ise kusma / regurjitasyon sıklığı günlük, haftada iki kereden daha az, seyrek ve asla seçeneklerinin olduğu ve sırayla 0 , 2, 4 ve 6 puanlarının verildiği son kısımdır. Anket sonucu toplam puan 1 ile 27 arasındadır, 1 en kötü ve 27 mükemmel bir gıda toleransı için maksimum değerdir. Ortalama gida tolerans skoru, tüm zaman aralıklarında normal popülasyondan önemli ölçüde daha düşük bulunmuştur. RYGB sonrası ilk yılda, özellikle postoperatif ilk yarıda ödem nedeniyle intolerans fazlayken, zamanla normalde dönerek RYGB'nin uzun vadede gida toleransını değiştirmediği sonucuna varılmıştır. Gastrik banttan sonra gıda toleransı olumsuz yönde önemli ölçüde değişmiştir ve bantta ayarlama yapılması önerilmiştir. $^{13,30}$

Amsterdam'da Boerlage ve arkadaşlarının RYGB'lı 175 hastanın 2 yıllık takibiyle yaptıkları çalışmada, hastaların preoparetif \%21,1'sinde gida intolerans1 görülürken, postoperatif \%66,9'unda görüldüğü tespit edilmiştir. $\mathrm{Bu}$ g1da intoleranslarının \%85'inin RYGB'den sonra yeni olduğu bildirilmiştir. Çalışmada hastaların \%10,9'u gıda intoleransından çok fazla etkilendiklerini belirtmişlerdir. ${ }^{31}$

Norveç Innlandet Hastanesi'nde RYGB ve vertikal sleeve gastrektomi (VSG) operasyonu geçiren 54 hastayla yapılan çalışmada; bariatrik cerrahi öncesi 6 ay ile sonrası 6 ay arasındaki gastrointestinal semptomlarındaki ve gıda toleransındaki değişiklikleri araştırılmıştır. Katılımcılara Suter'in gida tolerans anketi uygulanmış ve preoperatif 6.ayda gıda intolerans skorlar1 RYGB'de 24 ve VSG'de 25,5'ken, postoperatif 6 . ayda ise skor sirasiyla 23 ve 20 puan 
olarak bulunmuştur. Ameliyat sonrası bu hasta grubunda kırmızı et, pilav, makarna ve ekmeğe olan intolerans yüksekken, beyaz et, marul, balık ve sebzede intolerans gözlenmemiştir. ${ }^{32}$

Brezilya Onofre Üniversitesi Hastanesi'nde Godoy ve arkadaşlarının yaptığı gözlemsel bir çalışmada, hastaların sosyoekonomik durumu ile gida toleransı arasındaki ilişkiyi araştırmak amaçlı 47 kişilik hasta grubuna postoperatif ortalama 22. ayda Suter'in gida tolerans anketi uygulanmıştır. Hastaların \%38,3'ünde kırmızı et tolerasyonu görülmesine rağmen ortalama gida tolerans skoru 23 olarak bulunmuş ve sonuçlar iyi olarak değerlendirilmiştir. Ayrıca sosyoekonomik durumu orta sınıf olarak kabul edilen bireylerin (gıda tolerans skoru 24), daha düşük sınıftaki kişilere göre (gida tolerans skoru 21) gidalara daha iyi tolerans gösterdiği bulunmuştur. ${ }^{33}$

İsrail'de Schweiger ve arkadaşlarının 218 katılımcı ile gerçekleştirdiği çalışmada (99 RYGB, 14 BPD/DS, 56 LSG ve 49 AGB operasyonu) hastalar 3-6 ay, 6-12 ay ve 12 ay üzeri olarak üç periyotta takip edilmiştir. Erken dönem olan ameliyat sonrası 3-6 aylar arasında, daha uzun dönemlere oranla anlamlı derecede düşük gıda tolerans skoru (17,2 puan) bulunmuştur. Hastalar RYGB sonrası kırmızı et, tavuk, balık ve pirinç tüketiminde zorlanırken, SG sonrası salata, sebze, ekmek ve makarnada zorlanmışlardır. AGB operasyonu geçiren hastalar, tüm işlemlere oranla daha düşük tolerans puanına sahip oldukları ve bu grupta kusma sıklığının daha fazla olduğu bulunmuştur. Anketin cerrahi işlemden 12 ay ve sonrası için tolerans puanı ortalama 20,9 olarak bulunmuştur. $^{22}$

Gıda intoleransı ve bazı yiyecekleri yeme zorluğu De Zwaan ve arkadaşlarının çalışmasında RYGB'den 1835 ay sonra 59 hastanın \%30,5'inde gidaları sürekli çiğneme ve tükürme, \%60'indan fazlasında kusma olduğu bildirilmiştir. Sık kusma ve çeşitli gıdalardan kaçınma nedeniyle yeme kalitesinin düşmesine ve bazı hastalarda yumuşak ve yarı sıvı yüksek kalorili gidalara yönelmelerine neden olduğu sonucuna varılmıştır. Ayrıca, bunun sadece kilo verme sürecinin durmasına değil, aynı zamanda sık kusma ve çeşitli yiyecekleri yiyememe nedeniyle beslenme eksikliklerine de neden olabileceği endişesi vardır. ${ }^{34}$

\section{Gıda İntoleransının Etkilediği Diğer Faktörler}

G1da intoleransı, bariatrik cerrahi prosedürleri sonrası incelenmesi gereken bir konudur. ${ }^{18}$ Cerrahi sonras1 kırmızı et, tavuk eti, süt ve süt ürünlerini tolere etmek önemlidir, çünkü bu besinler ana protein kaynaklarıdır. $\mathrm{Bu}$ nedenle yaşanan intoleranslar postoperatif yaşanan bazı beslenme eksikliklerini açıklayabilir. ${ }^{11,35}$ Cerrahi sonrası hastaların; gıdaların tat ve kokusunda değişiklikler olduğunu belirterek gıda tercihlerini değiştirmeleri de bu duruma olumsuz katkıda bulunabilir. $^{23}$ İntolerans zamanla azalma eğiliminde olsa da, belirli besinlerin intoleransı nedeniyle hastalarda oluşan korku da süreci uzatabilir. ${ }^{25}$ Gıda intoleransı; birçok hastanın yüksek kalorili yarı sıvı bir diyete geçmesi sonucu kilo alımına neden olabilir ve bu durum kişilerin ruhsal ve mental sağlığını da etkileyebilir. ${ }^{31,35,36}$ Postoperatif takipte diyetin her durumda kontrol edilememesi; sadece cerrahi prosedürün türüne değil; çeşitli psikolojik, davranışsal ve bireysel kalıplara da bağlidır. $^{37}$

Bariatrik cerrahi hastaları ameliyattan yıllar sonra sürekli bakım gerektiren tıbbi ve psikososyal zorluklarla karşı karşıyadır. Örneğin, bir hasta ameliyat ile tüm fazla kilosunu kaybedebilir ve komorbiditelerini çözebilir, ancak sadece su ve ekmeği tolere edebilirse, muhtemelen ameliyatın başarısız olduğunu düşünecektir. Bu nedenle bariatrik cerrahi sonrası gıda toleransını değerlendirilirken; preoperatif gida toleransını bilmek ve hastayı yaşam boyu takip etmek gerekir. ${ }^{38}$ Dikkate alınması gereken bir diğer değişken takip süresidir. Gıda intoleransı postoperatif ilk yılda sıkça yaşanırken, uzun dönemde preoperatif seviyeye yükselmektedir. Bu nedenle gida intolerans1; bariatrik cerrahiden sonra uzun süreli büyük bir endişe kaynağı değildir ve gelecek çalışmalar gıda intoleransını postoperatif ilk yılda iyileştirmenin yolunu bulmak için yapılabilir. ${ }^{18}$

Gıda toleransı bariatrik cerrahi sonrası yaşam kalitesi ile ilişkilidir. ${ }^{39}$ Morbid obezite için en etkili tedavi seçeneği olan bariatrik cerrahi sonrası sağlıklı ve kaliteli bir diyet; yaşam memnuniyetini, mutluluğu, özsaygıyı ve iyimserliği arttırdığı için yaşam kalitesi ile ilişkilendirilebilir. Çünkü bariatrik cerrahinin başarısı sadece aşırı ağırlık kaybı değil, yaşam kalitesi ile de değerlendirilir. ${ }^{40,41}$

\section{SONUÇ}

Bariatrik cerrahi sonrasında beslenme yetersizliklerini gözlemlemek için, cerrahlar ve diyetisyenler arasında multidisipliner ve interdisipliner işbirliği sağlanması gerekmektedir. Bariatrik cerrahi uygulamaları bireylerin çoğunluğunda çok başarılı olmasına karşın, yöntemlerden herhangi biri daha mükemmel değildir. En doğru yaklaşım bireye en uygun cerrahi yöntemi belirlemek ve cerrahi sonrası yeni sorunların oluşmasını engellemek için hastayı uzun süreli takip etmektir. Bariatrik cerrahi sonrası bazı besinlerin tüketiminde intolerans yaşanmaması için şu öneriler uygulanabilir;

- Besinler iyi pişirilmeli ve iyi çiğnenmeli

- Yemek süresi en az 20 dakika olmalı

- Besinler küçük porsiyonlarda en az $30 \mathrm{kez}$ çiğnenmeli

- İntolerans yaşanan besinler alternatifleri ile değiştirilmeli 
- Doygunluk geldiğinde yeme-içme sonlandirilmalı

- Katı ve sıvı besinler bir arada tüketilmemelidir.

\section{KAYNAKÇA}

1. T.C Sağlık Bakanlığı, Türkiye sağlıklı beslenme ve hareketli hayat programı (20102014) https://hsgm.saglik.gov.tr/tr/beslenme hareket-haberler/türkiye-sağl1kl1-beslenmeve-hareketli-hayat-program1-2018-2023güncelleme-çalıștayı.html Erișim tarihi: 27 Subat 2014.

2. World Health Organization. Obesity and Overweight. Obesity and overweight - World Health Organization www.who.int > Erișim tarihi: 5 May 2013.

3. Sağlık Bakanlığı, 2015. Sağlık için obezite ile mücadele https://www.saglik.gov.tr/TR, 11692/obezite.html Erişim tarihi: 08 Ekim 2016.

4. Greenway FL, Smith SR. The future of obesity research. Nutrition. 2000;10(16):976982.

5. Akbulut G. Erişkinlerde şişmanlığın diyet tedavisindeki güncel yaklaşımlar ve fiziksel aktivitenin önemi. Mised. 2010;23:86-90.

6. Adachi Y. Behavior therapy for obesity. JMAJ. 2005;48(11):539-544.

7. Bariatric Surgery Procedures-ASMBS. American Society for Metabolic and Bariatric Surgery. https://asmbs.org/patients/ bariatric-surgery-procedures Erișim tarihi: 5 Aralık 2017.

8. Gastrointestinal surgery for severe obesity: National institutes of health consensus development conference statement. Am J Clin Nutr. 1992;55(2):615-619.

9. Yildiz G, Ersoy G. Bariatrik cerrahi sonrası beslenme yetersizlikleri ve diyet tedavileri. Bes Diy Derg. 2015;43(2):166-173.

10. Batar N. Bariatrik cerrahide beslenme ilkeleri. Bakırköy Tıp Dergisi. 2019;16:32332.

11. Türkiye Endokrinoloji ve Metabolizma Derneği. (TEMD). (2018). Bariyatrik Cerrahi Kilavuzu. Ankara. 1. Basım: Nisan 2018.

12. Batar N, Alphan ME. Sleeve gastrektomi sonrası ilk altı ayda besin ögeleri alımının bazı biyokimyasal parametrelere etkisi. Düzce Tlp Fak Derg. 2019;21(3):223-232.

13. Suter M, Calmes JM, Paroz A, Giusti V. A new questionnaire for quick assessment of food tolerance after bariatric surgery. Obes Surg. 2007;17:2-8.

14. Gloy VL, Briel M, Bhatt DL, et al. Bariatric surgery versus non-surgical treatment for obesity: a systematic review and meta- analysis of randomised controlled trials. BMJ. 2013;347:1-1.

15. Jakobsen GS, Smastuen MC, Sandbu R, et al. Association of bariatric surgery vs medical obesity treatment with long-term medical complications and obesity-related comorbidities. JAMA. 2018;319:291-301.

16. Akoğlu A, Oruç M. Metabolik gida intoleransları. Harran Tarım ve Glda Bilimleri Derg. 2018;22(2):284-295.

17. Gomes DL. Nutritional complications after bariatric surgery. Annals of Surgery and Perioperative Care. 2016;1-2.

18. Valderrama OC, Pernaute AS, Rubio-Herrera MA, Domínguez-Serrano I, Torres-García AJ. Long-Term food tolerance after bariatric surgery: comparison of three different surgical techniques. Obes Surg. 2017.

19. Sarwer DB, Moore RH, Spitzer JC, Wadden TA, Raper SE, Williams NN. A pilot study investigating the efficacy of postoperative dietary counseling to improve outcomes after bariatric surgery. Surg Obes Relat Dis. 2012;8: 561-568.

20. Kvehaugen AS, Farup PG. Changes in gastrointestinal symptoms and food tolerance 6 months following weight loss surgery: associations with dietary changes, weight loss and the surgical procedure. BMC Obes. 2018;5:29,2-9.

21. Dargent J. Isolated food intolerance after adjustable gastric banding: A major cause of long-term band removal, Obes Surg.2008;18:829-832.

22. Schweiger C, Weiss R, Keidar A. Effect of different bariatric operations on food tolerance and quality of eating. Obes Surg. 2010;20:1393-1399.

23. Graham L, Murty G, Bowrey DJ. Taste, smell and appetite change after roux-en-y gastric bypass surgery. Obes Surg. 2014.

24. Busetto L, Dicker D, Azran C, et al. Practical recommendations of the obesity management task force of the european association for the study of obesity for the post-bariatric surgery medical management. Obes Facts. 2017;10:597-632.

25. Nicoletti CF, Parenti de Oliveira BA, Barbin R, Marchini JS, Junior WS, Nonino CB. Red meat intolerance in patients submitted to gastric bypass: a 4-year follow-up study. Surg Obes Relat Dis. 2015;1-5.

26. Grosse CS, Cope VC. Dietary fibre intake and bowel habits after bariatric surgery: a structured literature review. Obes Surg. 2019.

27. Afshar S, Kelly SB, Seymour K, Woodcock $\mathrm{S}$, Werner AD, Mathers JC. The effects of bariatric procedures on bowel habit. Obes Surg. 2016; 26:2348-2354. 
28. Huang $\mathrm{CH}$. Essentials and controversies in bariatric surgery. Hirvatistan:IntechOpen; 2014.

29. Karadayı A, Türker PF. Dumping sendromunda nutrisyon. Güncel Gastroenteroloji. 2016;20(3):227-233.

30. Katsogridaki G, Zacharoulis D, Galanos A, Sioka E, Zachari E, Tzovaras G. Validation of the suter questionnaire after laparoscopic sleeve gastrectomy in the Greek population. Clin Nutr ESPEN. 2018;28:153-157.

31. Boerlage T, Westerink F, Gerdes V, Changes in gastrointestinal complaints and food intolerances after roux-en-y gastric bypass surgery. Surg Obes Relat Dis. 2017;13(10):181.

32. Blom Hogestol IK, Aasbrenn M, Chacal Kummen M. et al. Irritable bowel syndromelike symptoms and health related quality of life two years after Roux-en-Y gastric bypass- a prospective cohort study. BMC Gastroenterol. 2019;19(204):2-11.

33. Godoy CMA, Caetano AL, Viana KRS, Paiva de Godoy E, Barbosa ALC, Ferraz EM. Food tolerance in patients submitted to gastric bypass: the importance of using an integrated and interdisciplinary approach. Obes Surg. 2012;22:124-130.

34. De Zwaan M, Hilbert A, Swan-Kremeier S, et al. Comprehensive interview assessment of eating behavior 18-35 months after gastric bypass surgery for morbid obesity. Surg Obes Relat Dis. 2010;6:79-87.
35. Xanthakos SA. Nutritional deficiencies in obesity and after bariatric surgery. Pediatr Clin North Am. 2009;56(5):1105-1121.

36. Pehlivan M, Aksoydan E. Yetişkin kadınlarda vücut ağırlığının mental sağlığa etkisi. Beslenme ve Diyet Dergisi. 2012;40(1):12-21.

37. Gobato RC, Cazzo E, Baltieri L, Modena DAO, Chaim EA. Food intolerance 1 year after banded roux-en-y gastric bypass. Obes Surg. 2018.

38. Geraci AA, Brunt A, Marihart C. The work behind weight-loss surgery: a qualitative analysis of food intake after the first two years post-op. ISRN Obes. 2014.

39. Overs SE, Freeman RA, Zarshenas N, et al. Food tolerance and gastrointestinal quality of life following three bariatric procedures: adjustable gastric banding, Roux-en-Y gastric bypass, and sleeve gastrectomy. Obes Surg. 2012;22(4):536-543.

40. Kirkil C, Aygen E, Korkmaz MF, Bozan MB. Quality of life after laparoscopic sleeve gastrectomy using BAROS system. $A B C D$ Arq Bras Cir Dig. 2018;31(3):1385.

41. Sanlier N, Pehlivan M, Sabuncular G, Sevinç Bakan S, Isguzar Y. Determining the relationship between body mass index, healthy lifestyle behaviors and social appearance anxiety. Ecol Food Nutr. 2018,57(2):124-139. 